\title{
Lagged Cells
}

\author{
Alan B. Saul \\ Department of Ophthalmology, Medical College of Georgia, Augusta, Ga., USA
}

\section{Key Words}

Lateral geniculate nucleus • Thalamus • Response timing •

Direction selectivity $\cdot$ Synaptic triad

\begin{abstract}
The timing of the retinal input to the lateral geniculate nucleus is highly modified in lagged cells. Evidence is reviewed for how the responses of these cells are generated, how their structure and function differs from their nonlagged neighbors, and what their projections to cortex might do.
\end{abstract}

Copyright $\odot 2008$ S. Karger AG, Base

\section{Introduction}

Hubel and Wiesel [1] reported that receptive fields in the lateral geniculate nucleus (LGN) were much like those of retinal ganglion cells, with concentric center/surround receptive fields. This contrasted with their finding [2] that cortical receptive fields were oriented. Hundreds of other studies over the next 20 years detailed the cells along this pathway from many points of view. It is therefore surprising that something fundamentally new was found by David Mastronarde in 1980. Mastronarde, at the time a technician in the lab of Mark Dubin at the University of Colorado at Boulder, realized that there were cells in the cat's lateral geniculate nucleus that had not been previously appreciated. His recognition of lagged cells has still not been widely disseminated, and the topic has largely been restricted to technical papers (but see $[3,4])$. This review will compile some of this work in a less technical form. I begin with some background, and then describe Mastronarde's initial findings and subsequent work by several labs that described the properties of lagged cells and contrasted them with nonlagged cells. This leads to a model for how lagged cells are created in the LGN. I then consider what these cells might be good for, emphasizing the proposal that they contribute to the generation of direction selectivity in cortex. Finally, I point out directions for future research, and outline some of the instructive lessons this story holds for neuroscience in general.

\section{Background}

The part of the visual pathway considered here runs from the retina through the LGN to the cortex (fig. 1). Most of the cells in the LGN are relay neurons that have axons running in the optic radiations to cortex. Several cortical areas receive direct input from the LGN in the cat, including areas 17, 18, 19, and LS. Cortical area V1 receives almost all of the geniculocortical input in primates.

Retinal ganglion cells in cats come in 3 flavors: X, Y, and $\mathrm{W}$. These parallel pathways are preserved through the LGN, and the geniculocortical projection to areas 17 and 18 are dominated by $\mathrm{X}$ and $\mathrm{Y}$ cells, respectively. In primate retina and LGN, cells are divided into three major categories, $\mathrm{P}, \mathrm{K}$, and $\mathrm{M}$ cells that are largely segregated in the LGN, and project to distinct layers of V1.

These cell classes manifest structural and functional differences. Y cells, defined by their frequency-doubled

\section{KARGER \\ Fax +41613061234 \\ E-Mail karger@karger.ch}

www.karger.com

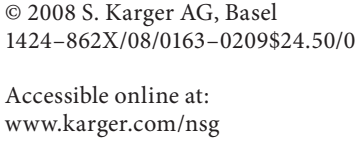

Alan B. Saul

Department of Ophthalmology

Medical College of Georgia

Augusta, GA 30912 (USA)

Tel. +1 706721 0695, E-Mail asaul@mcg.edu 


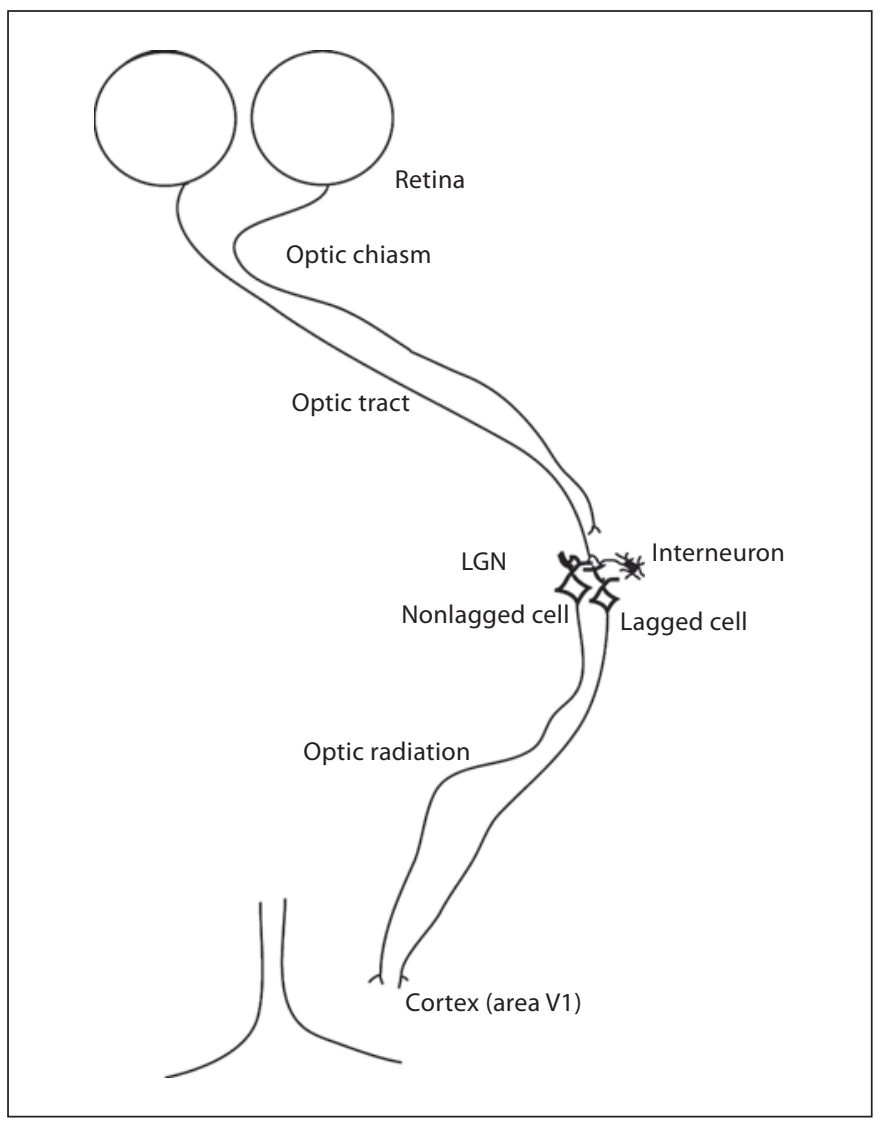

Fig. 1. Visual pathway. Retinal ganglion cell axons leave each eye via the optic nerves, and come together in the optic chiasm, where some fibers cross to project to the contralateral LGN. Axons from the two eyes terminate in separate layers of the LGN. Many LGN relay neurons (unfilled) receive nearly all of their retinal input from a single ganglion cell, which can diverge onto several LGN relay neurons. In particular, neighboring lagged and nonlagged LGN neurons might receive their input from the same retinal axon. Interneurons (filled) in LGN can mediate a sign inversion of the retinal input onto relay cells, creating feedforward inhibition. Relay cells project via the optic radiations to primary visual cortex.

response to counterphased gratings [5], have shorter latencies, larger and faster conducting axons, larger receptive fields, and more transient responses than $\mathrm{X}$ cells on average. Guillery [6] analyzed the morphology of cat LGN and classified cells into four groups. Guillery class 1 cells have large somata and smooth dendrites, whereas class 2 cells have numerous grape-like appendages on their dendrites. A correlation between the physiological $\mathrm{Y} / \mathrm{X}$ distinction and the anatomical class 1/class 2 division has been advanced, primarily through intracellular filling of physiologically identified cells [7]. However, this correlation does not hold up, as many X cells have class 1 morphology [8]. On the other hand, there appears to be a clear match between Guillery class 3 neurons and interneurons, and further structure-function relations will be discussed below.

The numbers of cells in each of these classes has been a subject of considerable dispute over the years. Two facts have sometimes been neglected in these estimates: the variations with eccentricity, and electrode sampling biases against small cells. The proportion of $Y$ cells falls off dramatically in central vision. Furthermore, the larger average soma size in $\mathrm{Y}$ cells has sometimes led to overestimates of their proportion because they are sampled more readily than the smaller $\mathrm{X}$ and $\mathrm{W}$ cells [9].

The fact that cortical cells have visual responses so unlike those observed in the LGN, whereas geniculate responses look much like those in the retina, led to considerable speculation about the function of the LGN. The general perception was that it served as an obligatory relay nucleus. Beyond this, the main proposal concerned its role in gating the visual signals on their way to cortex. For example, during sleep the LGN could serve to block the retinal input to cortex. This hypothesis is consistent with the large extraretinal projection to the LGN, mainly from cholinergic neurons in the brainstem reticular formation. This projection is activated during waking states, and serves to modulate activity in both LGN and visual cortex. The LGN could also function to focus attention on specific parts of the visual scene, perhaps through the massive corticofugal feedback to the LGN [10].

Efforts have been made to delineate the functions carried by the primate $\mathrm{M}$ and $\mathrm{P}$ pathways, and the cat $\mathrm{X}$ and $\mathrm{Y}$ streams. A common, though poorly supported view is that $\mathrm{X}$ and $\mathrm{P}$ cells carry the signals needed to recognize the forms of objects, whereas $\mathrm{Y}$ and $\mathrm{M}$ cells mediate the perception of motion. This idea stems from the fact that $\mathrm{Y}$ and $\mathrm{M}$ cells respond to rapidly moving stimuli that fail to excite $\mathrm{X}$ and $\mathrm{P}$ cells. In fact, $\mathrm{X}$ and $\mathrm{P}$ cells also respond well to motion, but require smaller stimuli. Purely temporal differences between $\mathrm{X}$ and $\mathrm{Y}$, or between $\mathrm{P}$ and $\mathrm{M}$ cells, are small.

\section{Mastronarde's Recognition of Lagged Cells in the Cat LGN}

Because many LGN cells receive the bulk of their excitation from a single retinal afferent, and because retinal ganglion cells are laid out across the retina in a reg- 


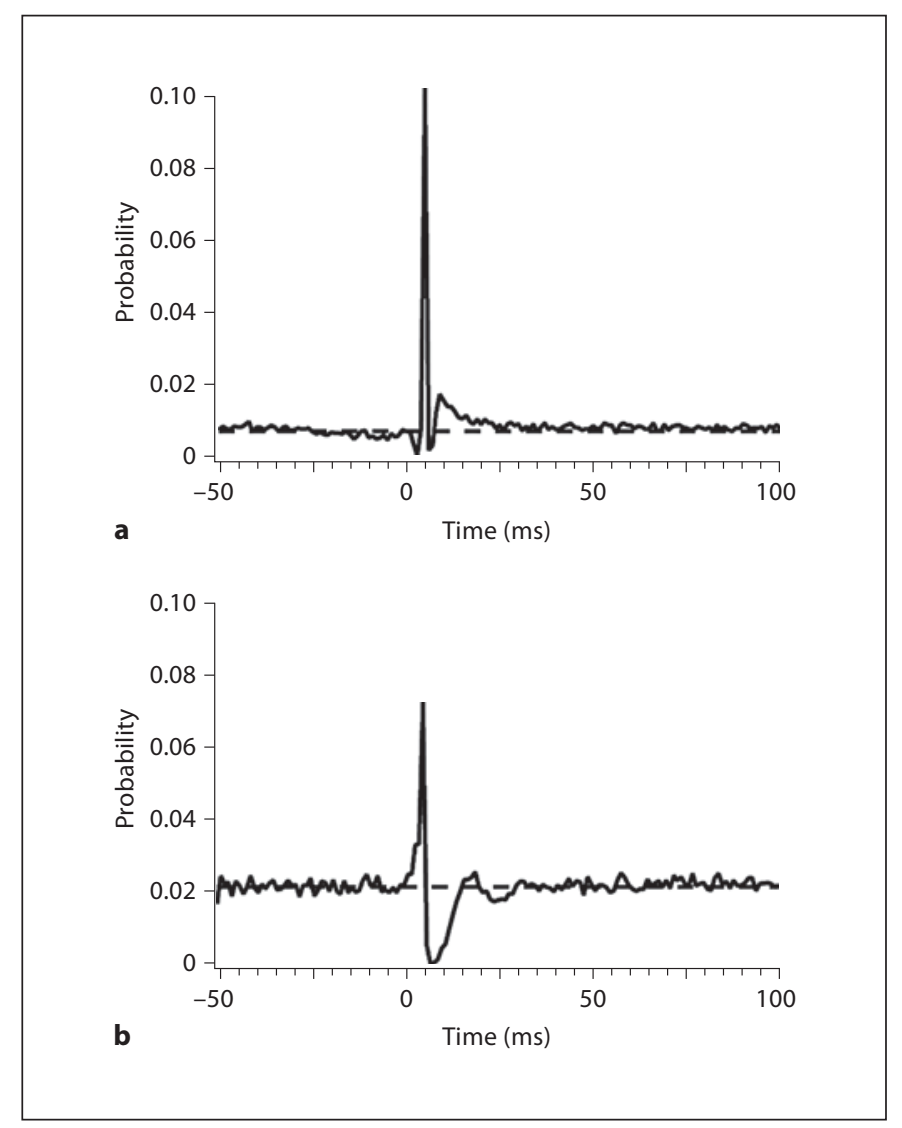

Fig. 2. Cross-correlograms. LGN cell firing is shown relative to retinal cell firing. Cells were stimulated with static spots. Dashed lines show the baseline probabilities. a Nonlagged X cell. b Lagged $\mathrm{X}$ cell. Data provided by David Mastronarde.

ular sheet, simultaneous recording of geniculate cells and their afferents is feasible and productive, though nonetheless heroic. A typical result in the form of a cross-correlogram between an X cell in cat LGN and a retinal $\mathrm{X}$ cell is shown in figure $2 \mathrm{a}$. Following a latency of $5 \mathrm{~ms}$, the probability of seeing a spike in the LGN cell following a spike in the retinal cell rises sharply, indicating that this retinal cell strongly excites the geniculate cell.

Mastronarde [11] found that some LGN cells had cross-correlograms like that in figure $2 \mathrm{~b}$. These lagged cells were single-input relay neurons that nonetheless were poorly driven by their excitatory afferent. Following an initial brief increase in the probability of seeing a spike in the lagged cell $5 \mathrm{~ms}$ after a retinal spike, the lagged cell shows a decreased probability of firing lasting several

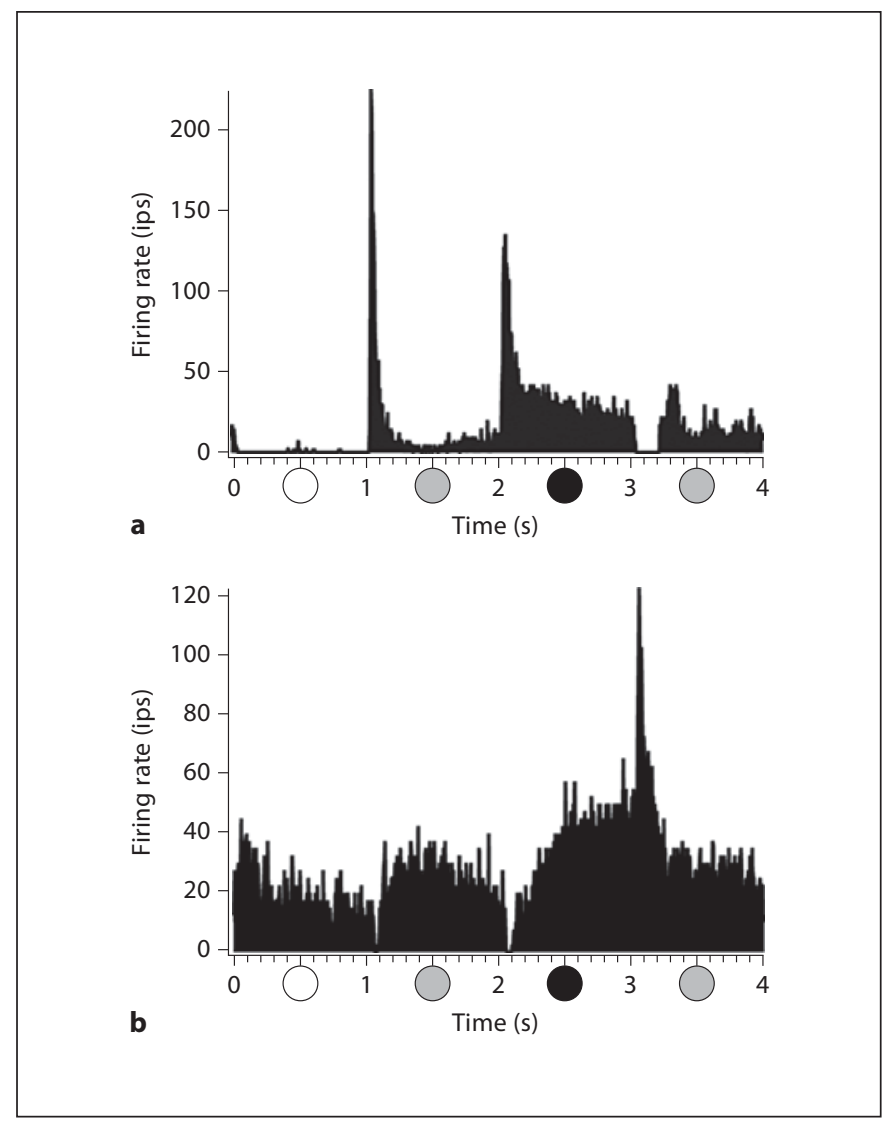

Fig. 3. Responses to flashing spots. The luminance of a small spot centered in the receptive field was modulated in 4 steps. Each step lasted $1 \mathrm{~s}$. The cycle was repeated 80 times, and spikes were accumulated in bins corresponding to time during the stimulus cycle. a An OFF-center nonlagged X cell was tested with a $0.5^{\circ}$ spot. b An OFF-center lagged X cell was tested with a $0.3^{\circ}$ spot.

milliseconds. Thus, the sole excitatory input to the cell has the effect of actually inhibiting it!

Mastronarde [12] demonstrated that $\mathrm{X}_{\mathrm{L}}$ (lagged $\mathrm{X}$ cells) and $\mathrm{X}_{\mathrm{N}}$ (nonlagged $\mathrm{X}$ cells; Mastronarde called these $\mathrm{X}_{S}$ ) cells differed on several independent measures. Although both groups had similar latencies to spike generation following electrical stimulation of the optic chiasm, the probability of obtaining a spike from lagged cells is much lower than for nonlagged cells. On the other hand, the visual latencies of lagged cells are much longer than for nonlagged cells, as shown further below. One of the clearest distinctions turned out to be the latency after electrical stimulation of visual cortex. Antidromic latencies for nonlagged cells are less than $2 \mathrm{~ms}$, whereas lagged cells have latencies from 2 to $8 \mathrm{~ms}$, suggesting that they send much smaller axons to cortex. 


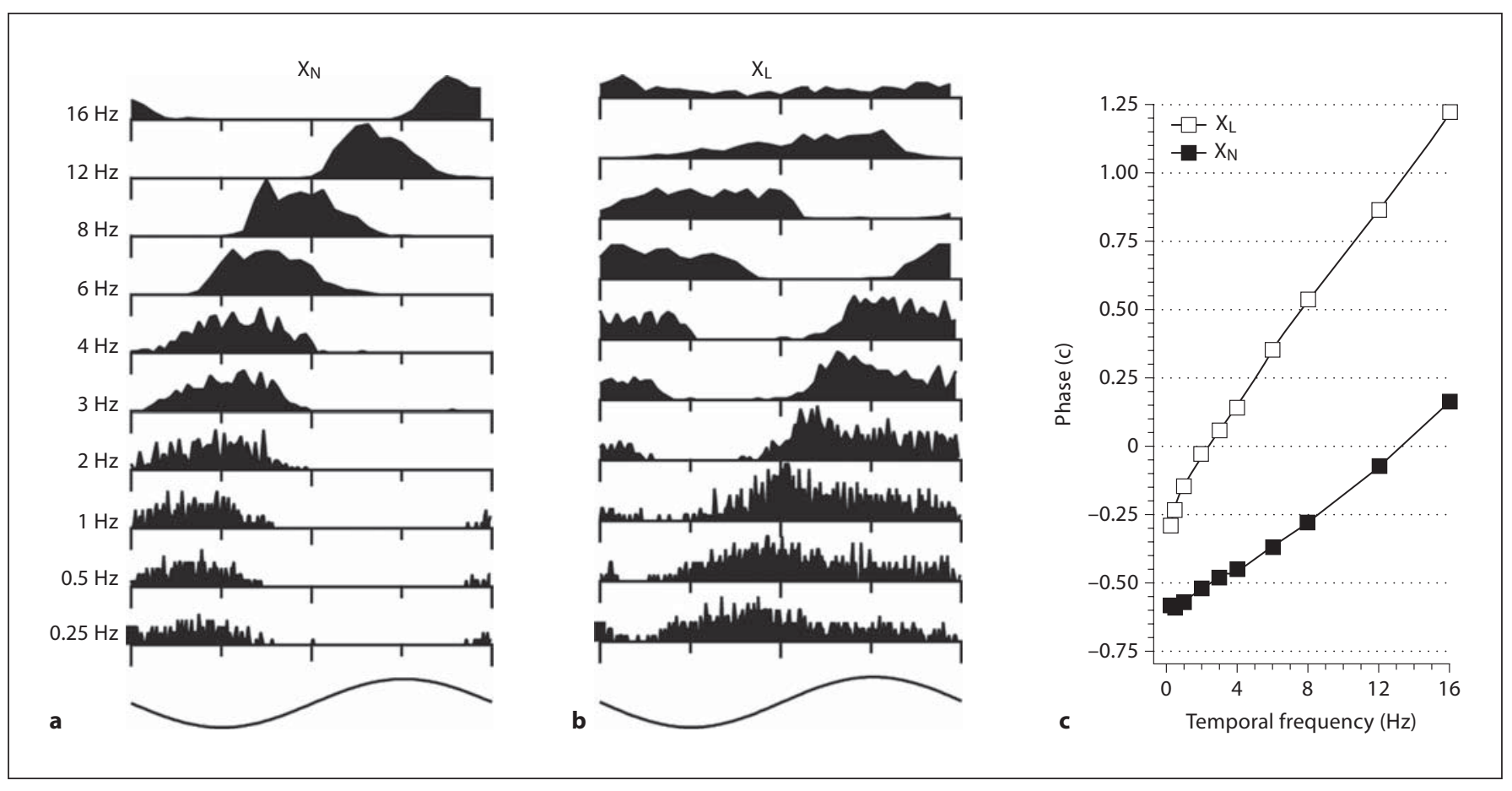

Fig. 4. Sinusoidal tests. The spot used for figure 3 was modulated sinusoidally in time, at a series of frequencies. The histograms in $\mathbf{a}$ and $\mathbf{b}$ show when spikes were evoked during the stimulus cycles, with the horizontal axis showing time during those cycles, the period being the reciprocal of the temporal frequency given at the left. Phase values derived from these histograms are plotted against temporal frequency in c. a Nonlagged cell from figure 3. b Lagged cell from figure 3. c Phase, in cycles, plotted against temporal frequency for the data in $\mathbf{a}$ and $\mathbf{b}$.

\section{Physiological Findings}

The primary sort of visual stimulus that has been used to test geniculate cells consists of a small spot centered in the receptive field whose luminance is modulated in time. Humphrey and Weller [13] modulated the luminance in four steps: brighter than background, equal to background, darker than background, and again at background luminance. This stimulus provides two luminance decreases and two increases, and often permits cells to exhibit background firing levels upon which inhibition can be observed. Figure 3 a shows the response of an OFF-center $\mathrm{X}_{\mathrm{N}}$ cell to such a spot. Transient excitatory responses are evoked about $50 \mathrm{~ms}$ after each luminance decrease. While the dark spot is on, this cell continues to fire, though at a reduced and declining level. At spot offset the activity is rapidly suppressed.

Figure $3 \mathrm{~b}$ displays a representative response histogram from an OFF-center $\mathrm{X}_{\mathrm{L}}$ cell. This cell fires primarily during the same two steps as the cell in $\mathrm{A}$, yet at different times. There is no excitatory transient response, but instead an inhibitory dip. Following the dip, the activity builds up and is sustained in this cell throughout the dark step. At the end of this step, rather than ceasing to fire like the nonlagged cell, the lagged cell fires transiently, the anomalous offset discharge.

This peculiar firing pattern in response to a step stimulus can be understood by appeal to a simpler stimulus, namely sinusoidal modulation of the same small spot. As shown in figure $4 \mathrm{a}$, the $\mathrm{X}_{\mathrm{N}}$ cell responds as the luminance of the spot is decreasing. This is why its response to the step stimulus occurs when the luminance decreases, at 1 and $2 \mathrm{~s}$. On the other hand, the OFF-center $\mathrm{X}_{\mathrm{L}}$ cell in figure $4 \mathrm{~b}$ responds as the luminance is increasing. Thus, in response to the step stimulus in figure $3 \mathrm{~b}$, the firing corresponds to times when the luminance is increasing, at $3 \mathrm{~s}$ in particular. The detailed characterization of these response timing differences involves measuring the phase of the response to the sinusoidally modulated stimulus, which will be described further below. 
Fig. 5. Impulse responses. Space-time maps were obtained by stimulating with pseudorandom noise. Narrow dark and bright bars were presented for $40 \mathrm{~ms}$ at a time at each of 32 positions. Spatiotemporal maps are shown $(\mathbf{a}, \mathbf{b})$ with dark areas representing OFF zones, and bright areas the inhibitory zones. Impulse response functions (c, $\mathbf{d}$ were derived by averaging across the receptive field centers. a, c Nonlagged cell from figures 3 and 4 gave a short-latency OFF response followed by a rebound. b, d Lagged cell from figures 3 and 4 responded with strong early inhibition, followed by the excitatory OFF response.

Fig. 6. Lagged P cell. A small spot changed colors as shown during 5-second trials while a monkey performed a fixation task. The spot's position was shifted to compensate for small eye movements [18]. This cell was in layer 5 .
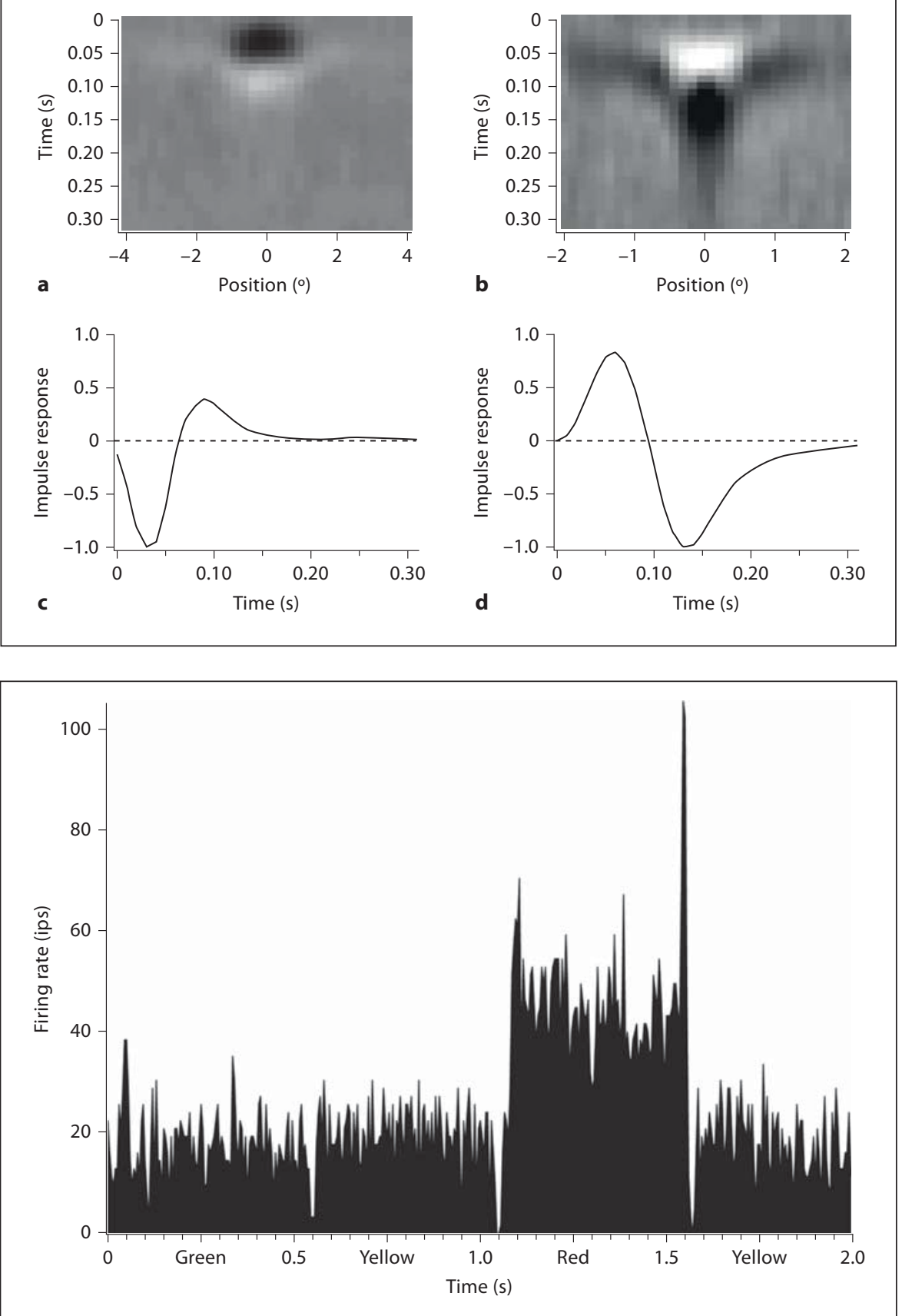

Response timing can also be derived from responses to pseudorandom noise stimulation. The impulse response function typically provides the characterization of the cell's temporal responses (fig. 5). Sustained responses correspond to monophasic, and transient responses to biphasic impulse responses. Nonlagged impulse responses are dominated by the initial phase, lagged by the second phase: the initial phase is inhibitory in lagged cells [14-16], whereas the second phase is inhibitory in nonlagged cells.

This discussion of the differences between lagged and nonlagged cells applies equally to X and Y [17], and P and $M$ cells [Saul, unpubl.]. The inputs from the retina appear to be subject to parallel mechanisms that create lagged responses in the LGN. These mechanisms affect response timing almost exclusively, and $\mathrm{X}$ and $\mathrm{Y}$ cells differ rela- 
tively little in response timing. $\mathrm{X}$ and $\mathrm{Y}$ cells differ spatially, and this distinction holds between $\mathrm{X}_{\mathrm{L}}$ and $\mathrm{Y}_{\mathrm{L}}$ cells. Lagged Y cells have large receptive fields and weak surrounds just like nonlagged Y cells. On the other hand, lagged $\mathrm{Y}$ cells have long visual and antidromic latencies like lagged $\mathrm{X}$ cells [17].

Five lagged cells ( $2 \mathrm{M}$ cells and $3 \mathrm{P}$ cells) have been recorded in awake monkey LGN [Saul, unpubl.]. Figure 6 illustrates lagged $\mathrm{P}$ cell responses from an alert rhesus macaque. This cell had a red-ON/green-OFF center, and the stimulus in this case was a small spot whose color was modulated between green, yellow, red, and back to yellow. A strong inhibitory dip and anomalous offset discharge were evoked. This cell was tuned to high temporal frequencies, had a very large action potential, and a high spontaneous firing rate. Its responses to sinusoidal modulation of the spot were lagged, and its impulse response derived from noise stimulation had the initial inhibition.

\section{Morphology}

Humphrey and Weller [8] filled physiologically identified cells with horseradish peroxidase (HRP) and analyzed their morphology. Their key finding was that all $\mathrm{X}_{\mathrm{L}}$ cells are small Guillery class 2 neurons. Class 2 cells have numerous grape-like appendages at dendritic branch points. These are the sites of the retinal input through a triadic synaptic arrangement that will be described below. All of the HRP-labeled $\mathrm{X}_{\mathrm{L}}$ cells had fine axons leaving the LGN, consistent with the long antidromic latencies of these cells.

The nonlagged cells were heterogeneous in their morphologies. Both $\mathrm{X}_{\mathrm{N}}$ and $\mathrm{Y}_{\mathrm{N}}$ cells could have either class 1 or class 2 morphologies, in contradiction to previous reports. Nonlagged cells with class 2 morphology had larger soma sizes than lagged cells. There were also $\mathrm{X}_{\mathrm{N}}$ cells with class 3 morphology. These cells are undoubtedly interneurons.

\section{Pharmacology}

Heggelund and Hartveit $[19,20]$ studied the effects of local applications of various neurotransmitter antagonists on lagged and nonlagged cells. They applied the $\mathrm{GABA}_{\mathrm{A}}$ blocker bicuculline while recording visual responses from lagged cells. This had the effect of eliminating the early inhibition and restoring an excitatory tran- sient discharge like that seen in nonlagged cells. However, the firing rate during the initial transient was still lower than seen in nonlagged cells, and latencies remained longer than in nonlagged cells despite being reduced from control values. This suggested that factors in addition to inhibition create lagged responses.

Applying antagonists to the excitatory amino acid receptors revealed a key factor. NMDA receptor blockers silenced lagged cells, while leaving some firing (particularly the transient responses) in nonlagged cells. NonNMDA blockers had little effect on lagged cells but strong effects on nonlagged cells. They concluded that virtually all of the excitatory input to lagged cells is mediated through NMDA receptors. Kwon et al. [21] obtained similar results.

Demeulemeester et al. [22] labeled cat LGN for the calcium-binding protein calbindin D-28K. The labeled relay cell population resembled the lagged cell group in soma size distribution. Confirmation of the hypothesis that calbindin labels lagged cells might enable recognition of lagged cells in vitro.

\section{Model for Generation of Lagged Responses}

The evidence suggests that the responses of lagged cells are derived from inhibition. This apparently $\mathrm{GABA}_{\mathrm{A}}$-mediated input must arrive early, since the retinal excitation is ineffective in causing spikes at short latencies. The anatomy indicates how to achieve this. The retinal input to many LGN cells, perhaps especially lagged cells, is encapsulated in glomeruli where the excitatory retinal terminal contacts both the relay cell dendrite and the interneuron dendrite (fig. 7), which is presynaptic to the relay cell, thus providing feedforward inhibition from the retina.

Mastronarde [11] showed how a related model explains the profound reduction in correlation at short latency. The model is consistent with the inhibitory dip observed in the visual responses and the effect of applying bicuculline. It also might help to understand the difficulty in driving lagged cells from electrical stimulation of the optic chiasm, since this stimulation would presumably evoke strong inhibition.

Lagged cells fire primarily following a period of inhibition. Since the inhibition is created by the retinal afferent, which responds much like nonlagged geniculate cells, lagged cells fire when nonlagged cell firing is declining. Examination of the histograms in figures 3 and 4 shows this correspondence. The anomalous offset dis- 
charge occurs when nonlagged cells stop firing, and the phase lag seen with sinusoidal stimulation follows this pattern.

This still leaves open the mechanisms responsible for the excitation or inhibitory rebound. Mastronarde [11] described an accommodation that could depend on membrane properties. He also speculated that low-threshold calcium channels could be responsible, since thalamic cells are known to produce calcium spikes following sufficient hyperpolarizations. McCormick [23] proposed that the A-current, a slowly-inactivating potassium current, might underlie lagged responses. He noted that the A-current would not account for the inhibitory dip and anomalous offset discharge without also invoking inhibitory mechanisms. Heggelund and Hartveit [19] implicated NMDA receptors, which are sensitive to inhibition. These receptors will only permit excitatory current to pass into the cell in the presence of their ligand and under relatively depolarized conditions. If the excitatory input to lagged cells arrives through NMDA receptors, then it would only become effective when the inhibition declined to the point that the membrane could be depolarized. The relative timing of inhibitory and excitatory synaptic potentials was proposed as a key factor. Given the slow rise time of the NMDA receptor-mediated excitation, and the faster non-NMDA receptors that appear to dominate the interneurons, the disynaptic inhibition can precede the monosynaptic excitation onto lagged cells. The long decay time of the excitatory potentials permits them to persist after the inhibition has faded, so the cell fires as its retinal input weakens.

Despite the voltage dependence of the NMDA receptor, excitation can be mediated by these receptors even at somewhat hyperpolarized potentials. Augustinaite and Heggelund [24] demonstrated the importance of this input in mouse LGN slices. NMDA receptor-mediated input may be responsible for the bulk of spikes, given that the AMPA receptor rapidly desensitizes.

A simulation of a conductance-based model that relies on these three ligand-gated mechanisms demonstrates their sufficiency in generating lagged responses (fig. 8). The model [Saul, unpubl.] was implemented as a system of differential equations describing the temporal evolution of membrane potential, activation and inactivation of sodium, potassium, and T-type calcium channels, calcium concentration, the hyperpolarization-activated $\mathrm{H}$ current, and the three ionotropic channels $\left(\mathrm{GABA}_{\mathrm{A}}\right.$, NMDA, and AMPA). Data provided by David Mastronarde were used to drive the model. Retinal spikes evoked synaptic currents in the model LGN cell, and model

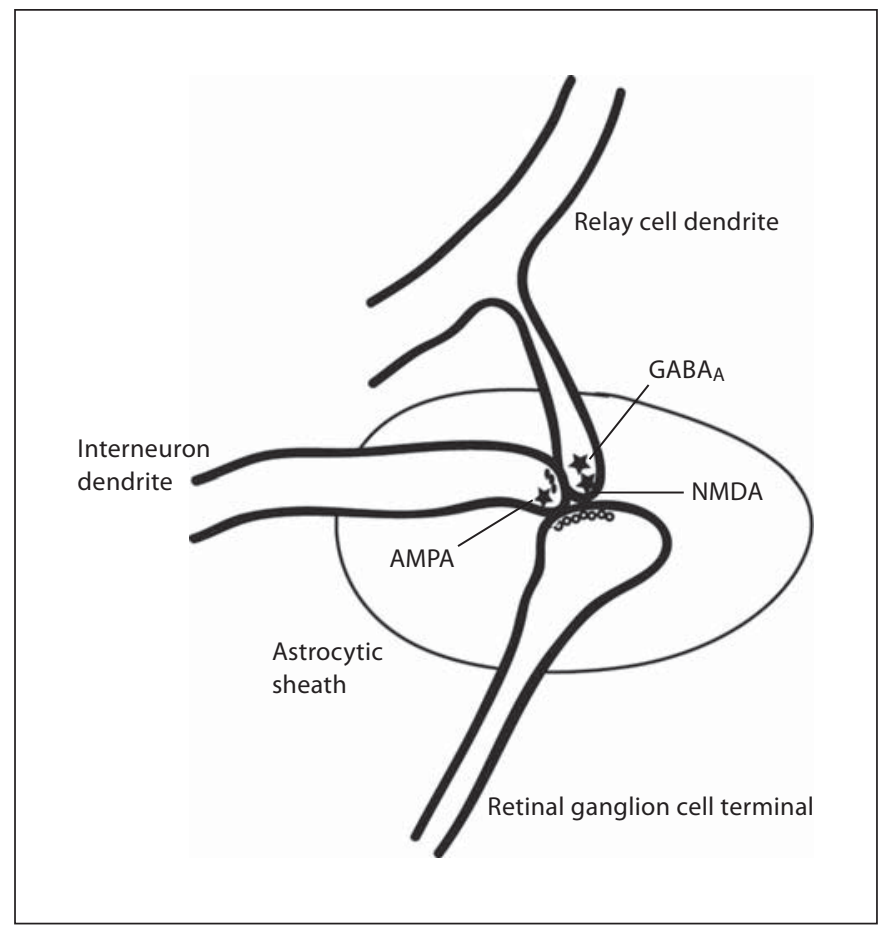

Fig. 7. Thalamic triad. Elements of synaptic triads in the LGN include a retinal terminal, a relay cell dendrite, and interneuron dendrites. The retinal terminal forms synapses onto both dendrites, and the interneuron is presynaptic to the relay cell. Triads are found in glomeruli, with all of the elements wrapped in a glial sheath. Evidence suggests that the excitatory synapse onto lagged cells depends on NMDA receptors, whereas synapses onto interneurons use AMPA receptors. Additional elements and receptors are known to participate in triads.

spikes were compared to actual recorded LGN spikes. In figure $8 \mathrm{a}$, green ticks mark retinal spikes that occur especially at the onset of the visual stimulus (black bar). In the presence of this strong retinal drive, the membrane potential remains at about $-55 \mathrm{mV}$ because of a strong $\mathrm{GABA}_{\mathrm{A}}$ conductance. The model cell begins to fire at about the same time as the actual cell did, and continues to fire throughout the duration of the ON period. At offset $(25,000 \mathrm{~ms})$, firing accelerates. Histograms averaged over the entire 26 -second run are shown in figure $8 \mathrm{~b}$. The model generates the inhibitory dip and anomalous offset discharge, but the firing rate is much lower than in the actual cell, and firing occurs late in the OFF period that is not present in the real cell. The individual ionotropic currents are separated in figure $8 \mathrm{c}$, illustrating the strong $\mathrm{GABA}_{\mathrm{A}}$ and NMDA and weak AMPA currents chosen for this particular simulation. At the onset of retinal firing, the outward $\mathrm{GABA}_{\mathrm{A}}$ current dominates, until the 


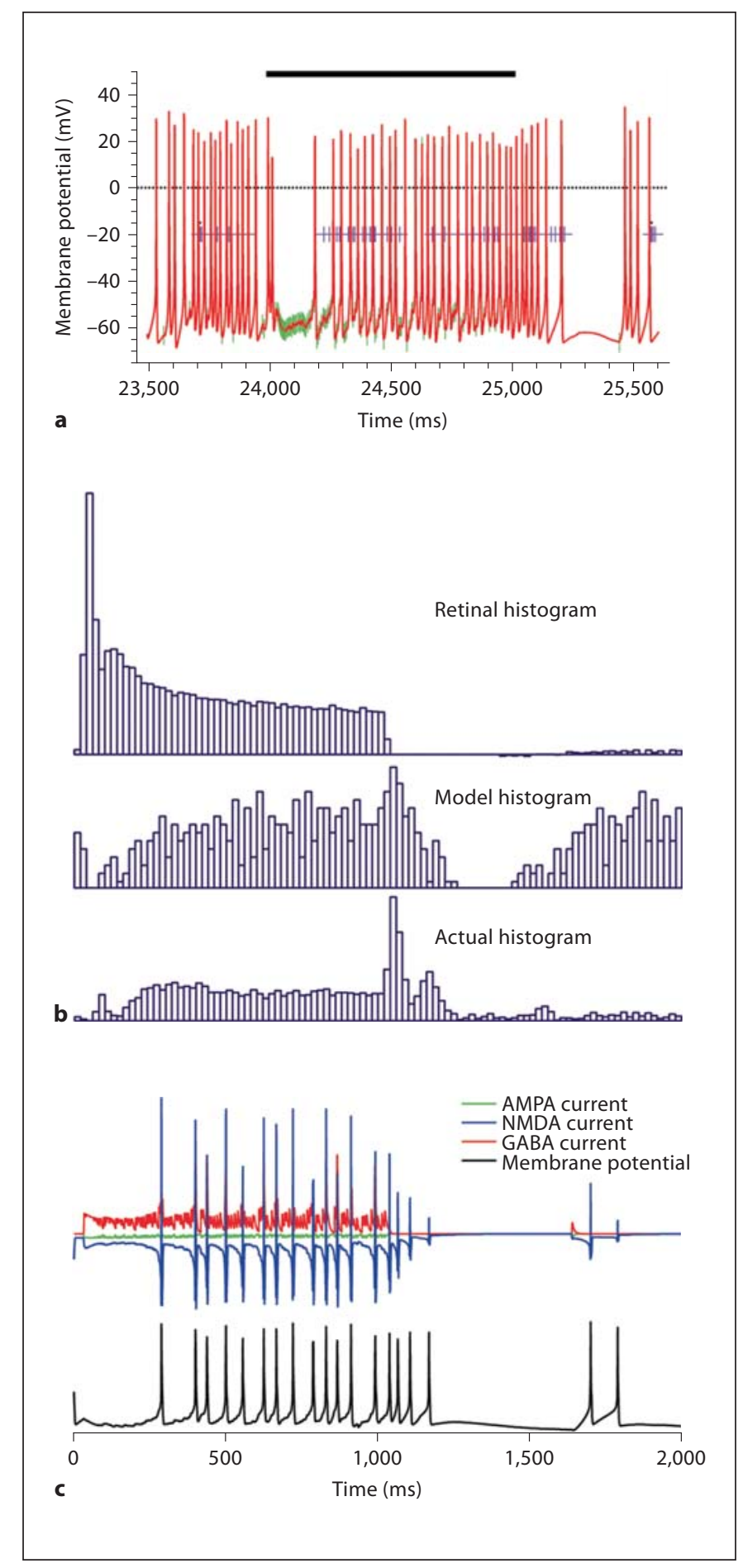

Fig. 8. Simulation of lagged responses. A conductance-based model consisting of 11 currents was solved numerically. In the case shown here, strong $\mathrm{GABA}_{\mathrm{A}}$ and NMDA and weak AMPA currents were used. Retinal spike times were used to drive the model, and the simulated firing was then compared to corresponding geniculate firing taken from Mastronarde's recordings. a Computed voltage trace (red) is shown for a small sample of data. The visual response was a flashing spot, with the ON portion
NMDA current eventually overcomes it and firing ensues. At stimulus offset (1 s), the $\mathrm{GABA}_{\mathrm{A}}$ current disappears, and the longer-duration NMDA current drives several spikes before it declines. Spikes are generated based on the interaction between the excitatory and inhibitory inputs, and the differing voltage dependences and decay times of the synaptic currents influence this process. These simulations provide evidence that lagged cell responses could emerge from these sorts of interactions. Direct experiments that test such models remain to be performed.

\section{Function}

Several ideas have been advanced as to the roles played by lagged and nonlagged cells. I will focus on their role in motion processing, although presumably they participate in multiple functions. First, however, are these neurons capable of playing a functional role, or are they only an experimental artifact or aberration?

\section{Brainstem Influence}

Humphrey and Weller [13] speculated that the brainstem input to the LGN might transform lagged cells into nonlagged cells. This could serve to gate the input to cortex, since lagged cells have lower responsiveness than nonlagged cells. The cholinergic input from the peribrachial brainstem varies with states of sleep and arousal [25]. In slow-wave sleep, many relay cells could have sluggish lagged responses, and the retinal signal to cortex would be toned down. In a waking state the brainstem activity increases and the relay cells might respond in a nonlagged fashion, providing stronger activation of cortex. Uhlrich et al. [26] reported that electrical stimulation of the peribrachial region could in fact change cells from lagged to nonlagged, consistent with this theory.

of the cycle indicated by the black bar above the traces. Retinal spikes are shown with green tick marks, and the simultaneously recorded LGN spikes are shown with purple crosses. b Averaged over the entire 26-second run, the retinal and actual LGN response histograms are compared to the simulated LGN response. c The three ionotropic currents are shown for a 2-second sample, along with the voltage trace. The AMPA current is negligible compared to the NMDA and GABA currents. 
Humphrey and Saul [27] and Hartveit and Heggelund [28] failed to confirm these results, however. Brainstem stimulation increases activity in all LGN cells, particularly enhancing the visual responses of lagged cells. The normally sluggish onset response of lagged cells becomes much sharper during brainstem activation, and latencies decrease. Nonetheless, latencies of lagged cells remain in the lagged range, and most tellingly, the early inhibition that is a hallmark of the lagged response to flashed stimuli is still present during brainstem stimulation. The cholinergic inputs do not seem to affect this early inhibition, which is presumably mediated by the presynaptic dendrites of geniculate interneurons. Therefore, brainstem activity does not transform lagged responses into nonlagged responses.

The general idea that lagged responses represent some sort of epiphenomenon, rather than an inherent property of certain neurons, is contradicted by several other results. The clearest evidence is that lagged responses have an anatomical correlate [8]. The exact relationships between the morphology and the physiology remain to be worked out, but lagged responses are seen only in a certain type of neuron, suggesting that not every relay cell can respond this way. Note that lagged cells have very fine axons and long corticogeniculate latencies, properties independent of their visual responses but providing another means to distinguish them from nonlagged cells. The notion that lagged responses represent a response mode that any relay cell might achieve under some global condition, such as sleep states, is also contradicted by the occurrence of simultaneous recordings of lagged and nonlagged cells [29], as well as recordings of lagged cells in alert monkey [Saul, unpubl.]. Finally, we discuss below evidence that lagged cells in the LGN provide an important input to cortical neurons that permits these cortical receptive fields to show their characteristic direction selectivity.

\section{Coverage}

Before proceeding to describe what we think lagged inputs do in cortex, note that the substrate is sufficient for the task. Mastronarde [30] computed a number referred to as coverage that describes how many cells of a given type exist for any given average receptive field. Both $\mathrm{X}_{\mathrm{L}}$ and $\mathrm{Y}_{\mathrm{L}}$ cells are numerous enough to provide full coverage of the visual field. Indeed, the $\mathrm{X}$ cell projection to cat area 17 is $40 \%$ lagged $[8,12]$. This suggests that it is worthwhile to consider what role this massive projection might play in cortex.

Lagged Cells

\section{Timing Differences between Lagged and Nonlagged Cells}

To describe what lagged cells might be good for, consider the sinusoidal stimulus mentioned above. This stimulus allows the response to be characterized by two numbers: one number tells how strong the response is, and the other number tells when the response occurs. This second number, response timing, is the key to understanding the lagged cell contribution to visual processing. The two numbers are referred to as amplitude and phase. They are derived by computing the first harmonic component of the response to the sinusoidally modulated stimulus; that is, the response is effectively modeled as a sinewave, and the height and position in time of this sinewave are used to characterize the response. The phase value captures when the response occurs relative to the stimulus. My convention is to call the time when the stimulus luminance peaks zero phase, and to increase phase values as the response occurs later in time. If the response occurs when the stimulus is at its darkest point, the phase value is a half cycle. Response phase values can be thought of as positions on a circle, for instance putting 0 cycles at the top ( 12 o'clock), 0.25 cycles at the right ( 3 o'clock), 0.5 cycles at the bottom (6 o'clock), and 0.75 cycles at the left ( 9 o'clock). Note that adding an integer to any phase value does not change its position on the circle; this can be thought of as going around the circle several times, coming back to the same point. Phase values a bit less than zero (e.g. 11 o'clock) represent phase leads; indicating that the response occurs before the stimulus (this is possible because the stimulus is ongoing, so it isn't that the response precedes all stimulus events). Phase values a bit greater than zero (1 o'clock) similarly represent phase lags relative to the stimulus. Since visual responses occur as $\mathrm{ON}$ or OFF types, with $\mathrm{ON}$ responses occurring near the luminance peak and OFF responses occurring near the luminance trough, I will refer to OFF responses as leading the stimulus when they have phase values just less than 0.5 cycles ( 5 o'clock) and lagging the stimulus when the phase value is just greater than 0.5 cycles (7 o'clock).

Nonlagged cells respond to a sinusoidally modulated spot with a phase lead relative to the stimulus at low temporal frequencies (fig. 4a), whereas lagged cells have a phase lag (fig. 4b). At higher temporal frequencies, cells fire at later points in the stimulus cycle because of the latencies between stimulus and response, which take up a greater part of a cycle as the cycle gets shorter. Saul and Humphrey [31] showed that the response phase behavior 


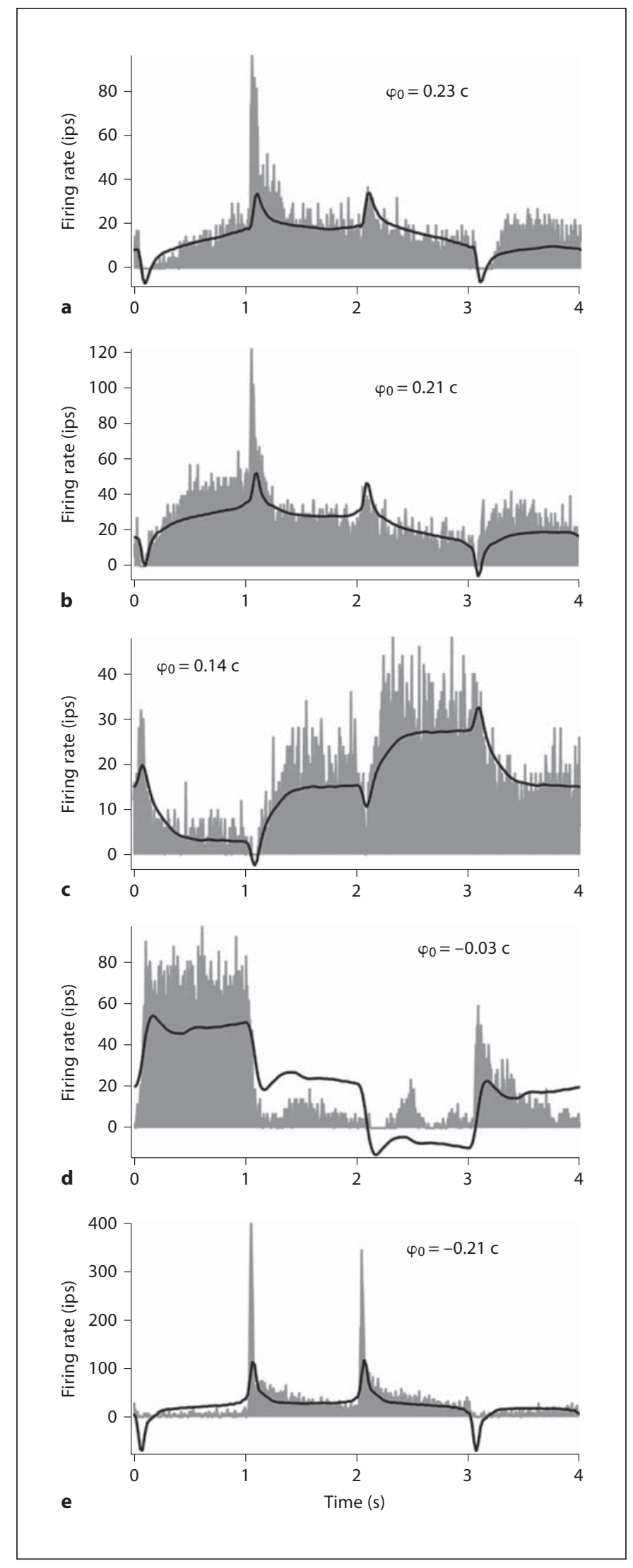

of lagged and nonlagged cells differs in two ways: as seen in figure 4, lagged cells fire about a quarter-cycle later than nonlagged cells at low temporal frequencies, and with increasing temporal frequency the rate of increase in phase is higher in lagged than in nonlagged cells.

Figure $4 \mathrm{c}$ illustrates this behavior by plotting response phase versus temporal frequency for these lagged and nonlagged cells from cat LGN. At low temporal frequencies, the lagged cell responds with a phase lag, whereas the nonlagged cell has a phase lead, giving a response phase difference between the cells of about 0.25 cycles. We call the extrapolation of the phase versus frequency data to $0 \mathrm{~Hz}$ absolute phase. With increasing temporal frequencies, response phase increases fairly linearly. The slope of the phase versus frequency line (which is a form of latency) is about $50 \mathrm{~ms}$ for the nonlagged cell and about $110 \mathrm{~ms}$ for the lagged cell. Thus, the quarter cycle difference at low frequencies grows to about a half cycle by 4 Hz. In alert monkey, lagged cells of both $\mathrm{M}$ and $\mathrm{P}$ types have phase lags at low frequencies, but latencies are similar for lagged and nonlagged cells.

An ON-center cell with an absolute phase lead responds as luminance increases. This means that for a flashed stimulus the response occurs primarily when the stimulus gets brighter. Larger absolute phase leads correspond to more transient responses, and absolute phase values closer to 0 cycles correspond to more sustained responses to a flashed stimulus. An absolute phase value of 0 cycles means that the response follows the stimulus, so the response to a luminance step looks much like the step, that is, sustained. When the absolute phase value exceeds 0 , as it does for lagged cells, the response occurs as the luminance decreases, despite the cell being ON-center. For a flashed stimulus, the response occurs primarily at the offset of the bright spot. Small absolute phase lags correspond to fairly sustained flash responses with small anomalous offset discharges, and larger absolute phase lags correspond to gradual buildups to large anomalous offset discharges. One can predict the timing of the flash response

Fig. 9. Linearity of timing. Responses to the 4-part flashing spot stimulus (gray histograms) are compared to linear predictions of these responses based on independent experiments using sinusoidal stimuli (solid lines). Absolute phase $\left(\phi_{0}\right)$ values are given for each cell, with the values for OFF-center cells shifted into the interval between -0.25 and 0.25 cycles. These 5 cells were all recorded in a single cat. a A very transient $\mathrm{OFF}_{\mathrm{L}}$ cell. b A transient OFF $X_{L}$ cell. c A sustained ON X $X_{L}$ cell. $\mathbf{d}$ A sustained OFF $X_{N}$ cell. e A transient $\mathrm{ON} \mathrm{X}_{\mathrm{N}}$ cell. 
of a cell from the intercept of the phase versus frequency plot $[14,15,31]$. Five examples are presented in figure 9 . These examples range from a transient nonlagged (fig. 9e) through sustained nonlagged (fig. 9d) and lagged (fig. 9c) cells to transient lagged cells (fig. 9a, b), with the absolute phase values ranging from near -0.25 cycles to near 0.25 cycles. The predictions capture the timing of the actual responses, but not the amplitudes, which are affected by nonlinearities. The continuum around the circle of timing is illustrated by comparing the OFF-center lagged cell in figure 9a with the ON center nonlagged cell in figure 9e. These responses are similar, and the linear predictions are especially close. These two cells differ nonetheless, primarily in peak firing rate, which is not predicted well. This might be explained in terms of the AMPA receptor dependence of nonlagged cells that enables higher firing rates. Thus, despite timing being continuous, the mechanisms underlying the different timings may vary more discretely. The lagged/nonlagged distinction represents an expansion of the sustained/transient spectrum from phase values between -0.25 and 0 cycles, as found in the retina, to the quadrant from 0 to 0.25 cycles. One can think of the retina as seeing only times between 9 and 12 o'clock and 3 and 6 o'clock, but the full cycle of response timing is present in the LGN.

\section{Direction Selectivity}

Determining the direction of a moving stimulus requires two or more signals that are separated in both space and time. In one direction of motion, these spatial and temporal separations add up, whereas in the other direction they are subtracted. Representing these spatial and temporal differences in terms of phase provides a simple characterization of what is needed to achieve direction selectivity. For one direction the signals should be in phase with each other and for the opposite direction they should be out of phase with each other. Constructive interference is then achieved in the preferred direction and destructive interference in the nonpreferred direction. For the spatial and temporal differences to add up to a half-cycle (out of phase) in one direction and subtract to give zero cycles (in phase) in the other direction, each should be a quarter-cycle. This scheme is known as spatiotemporal quadrature. Direction-selective receptive fields are built up from inputs that are in approximate spatiotemporal quadrature with each other.

Quarter-cycle differences in space are easy to find in the visual system. Receptive fields exist at any position in visual space, so that inputs separated by a quarter cycle are easily derived by selecting two appropriate cells.

Temporal quadrature is more difficult to achieve, particularly at low temporal frequencies. Over the range of $0.5-8 \mathrm{~Hz}$, a quarter cycle corresponds to $500-31.25 \mathrm{~ms}$. Just going from 0.5 to $1 \mathrm{~Hz}$ means changing the delay from 500 to $250 \mathrm{~ms}$. What neural mechanisms provide these sometimes long and varied delays? Latency differences on the order of tens of milliseconds exist in the LGN and visual cortex. No obvious candidate for generating temporal quadrature at low frequencies was known prior to the discovery of lagged cells, however.

From the discussion above, we see that lagged and nonlagged cells respond in approximate temporalquadrature at low temporal frequencies. Typical lagged and nonlagged cells respond about a quarter cycles apart at frequencies below about $4 \mathrm{~Hz}$. This is not achieved by latency differences. Instead, lagged cells derive their phase lag through mechanisms like those described above. Feedforward inhibition first inverts the retinal signal, which is similar in timing to nonlagged LGN cells. The excitatory activation in lagged cells arises with the decrease in this inhibition, creating a quarter-cycle advance in the inverted signal. These processes seem to operate in the frequency domain in that their effects shift phase rather than latencies.

However, latency is also affected, at least in cat LGN, perhaps because the mechanisms that create the phase lag require temporal integration. Lagged cells have longer integration times, or latencies, than nonlagged cells. This latency difference means that lagged and nonlagged cells do not remain in quadrature across all temporal frequencies. Instead, by about $4 \mathrm{~Hz}$ the phase difference is roughly a half-cycle.

In summary, direction selectivity requires spatiotemporal quadrature. Temporal quadrature could be obtained in cortex from lagged and nonlagged inputs. These inputs would provide the signals needed to obtain direction selectivity at low temporal frequencies, where it is most difficult to imagine mechanisms that create the long and varied time delays necessary. On the other hand, these inputs might not be sufficient to generate direction selectivity across a broad range of frequencies. Obtaining quadrature at higher frequencies is relatively easy, either by combining sustained and transient nonlagged inputs or by taking advantage of latency differences. In monkeys, where lagged and nonlagged latencies are similar, direction selectivity is easier to maintain across temporal frequency.

Neurosignals 2008;16:209-225 
Fig. 10. Timing distributions. From experiments with sinusoidally modulated stimuli, response phase vs. temporal frequency was plotted and lines were fit to those data. This gives two parameters, slope (latency) and intercept (absolute phase). These are plotted against each other for 81 cells from cat LGN and 229 positions inside cat cortical simple cell receptive fields. The LGN data are divided by cell type. Latency is scaled logarithmically, from 30 to $200 \mathrm{~ms}$.

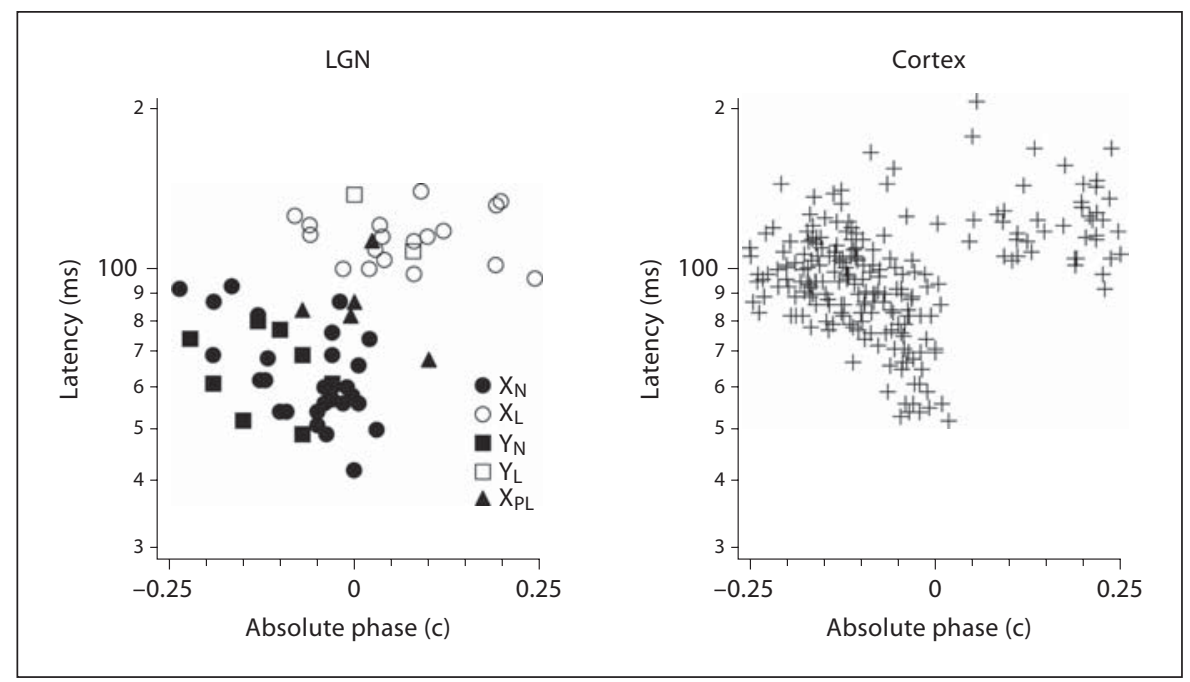

\section{Cortical Results}

Saul and Humphrey [31] proposed this role for lagged and nonlagged inputs to cortex without any direct evidence. Although all lagged cells are relay cells projecting to cortex based on antidromic activation from cortex and anatomical results showing that they all have axons leaving the LGN, little was known about their projections. Two earlier studies were reinterpreted with the discovery of lagged cells [13], and these studies indicate that the lagged input to cortex could terminate specifically in lower layer 4. First, Mitzdorf and Singer [32] performed a current source density experiment in which they recorded latencies of current sinks to electrical stimulation of the optic radiations at a series of depths through visual cortex. They reported long latency $(2-10 \mathrm{~ms})$ sinks in lower layer 4 , as opposed to shorter latency (1-2 ms) sinks in upper layer 4 . Their interpretation was in terms of $\mathrm{X}$ and $\mathrm{Y}$ inputs. However, nonlagged $\mathrm{X}$ and $\mathrm{Y}$ cells all have antidromic latencies less than $2 \mathrm{~ms}$. On the other hand, the ranges found in their study correspond closely to the antidromic latencies reported for lagged and nonlagged cells $[12,13]$. The other relevant study was a retrograde tracing experiment in which HRP dumps were made in localized regions of cortex. Leventhal [33] reported that, following small injections into lower layer 4 , a population of small cells was labeled in the LGN. The soma size distribution appears similar to that of lagged cells [8], consistent with the notion that these cells project specifically to lower layer 4.

To investigate the lagged projection a bit more directly, Saul and Humphrey [34] essentially repeated the ex- periments done in the LGN, but now on cortical simple cells. Rather than using a small spot, we used an elongated bar of optimal orientation for each cell. In addition, simple cells do not have a single receptive field center, so we tested each cell at a series of positions across their receptive fields. For each of these positions we modulated the bar's luminance sinusoidally in time at several temporal frequencies, and measured the amplitude and phase of the response. We then plotted the response phase versus temporal frequency. Just as in the LGN, we found that response phase could either lead or lag the stimulus at low temporal frequencies, and that positions that showed a phase lag also had longer latencies. Figure 10 shows the intercepts (absolute phase) and slopes (latency) for a sample of cortical receptive field positions, and compares this to similar data from the LGN. The LGN plot shows that lagged cells have long latencies and absolute phase lags, and nonlagged cells have short latencies and absolute phase leads. The cortical data reflect the association between absolute phase lags and long latencies ('lagged-like' timing), although more positions with absolute phase leads and long latencies are seen, with latencies being longer on average in cortex.

Positions that had lagged-like response timing were found in some, but not all simple cells. Cells showing several positions with lagged-like timing were located almost exclusively in lower layer 4 or upper layer 5 [34]. We thus confirmed the suggestion from the studies cited above that lagged cells might project specifically to deep layer 4.

These experiments permitted an analysis of what the observed timing might contribute to cortical response 
properties. An example of data from one experiment is shown in figure 11a. This lower layer 4 simple cell had an ON subzone in the middle of these graphs with OFF subzones above and below. Responses to the sinusoidally modulated bar are shown as a series of maps of the receptive field at each tested temporal frequency. Two cycles are shown for clarity. Note the clear orientation of the responses in space and time at low temporal frequencies. This orientation is characteristic of direction selective cells. The preferred direction is the direction in which responses come progressively earlier in time, downward in these plots. One can think of a stimulus evoking the pictured responses as it passes through each position in the receptive field; these responses sum to a much larger total response in the downward than in the upward direction. The amplitude and phase values derived from these histograms can be transformed from functions of space to functions of spatial frequency, yielding predictions of the response in each direction. Several studies have discussed the extent to which such predictions are accurate [35-43]. These data also address how well the responses in each direction are predicted as a function of temporal frequency. The space-time maps in figure 11a are oriented at low frequencies, but are less well-oriented at 4 and $6 \mathrm{~Hz}$. As illustrated in figure 11b, this corresponds to the cell's actual responses to drifting gratings, for which it was strongly direction selective up to $3 \mathrm{~Hz}$ but less direction selective at $4 \mathrm{~Hz}$ and above. The predicted tuning curves from the space-time maps in figure 11a are qualitatively similar to the actual responses.

\section{Temporal Frequency Tuning of Direction Selectivity}

The tendency seen in this particular cell is common in the population. Many cells are direction selective at low temporal frequencies, but lose their direction selectivity

Fig. 11. Spatiotemporal maps. A lower layer 4 simple cell was tested with sinusoidally modulated bars at a set of 16 positions and 7 temporal frequencies. Two cycles of the responses are shown for clarity. The luminance waveform is shown at the bottom. Numbers next to the scale bars at the upper right of each graph give the amplitude scale in impulses per second. Uncorrelated noise was presented simultaneously with the sinusoidally modulated bars to increase background activity. The graph in $\mathbf{b}$ gives the measured temporal frequency tuning for gratings drifting in each direction (solid line and filled symbols: preferred; dashed line and open symbols: nonpreferred) along with the predictions generated from the data in a (solid and dotted lines without markers).

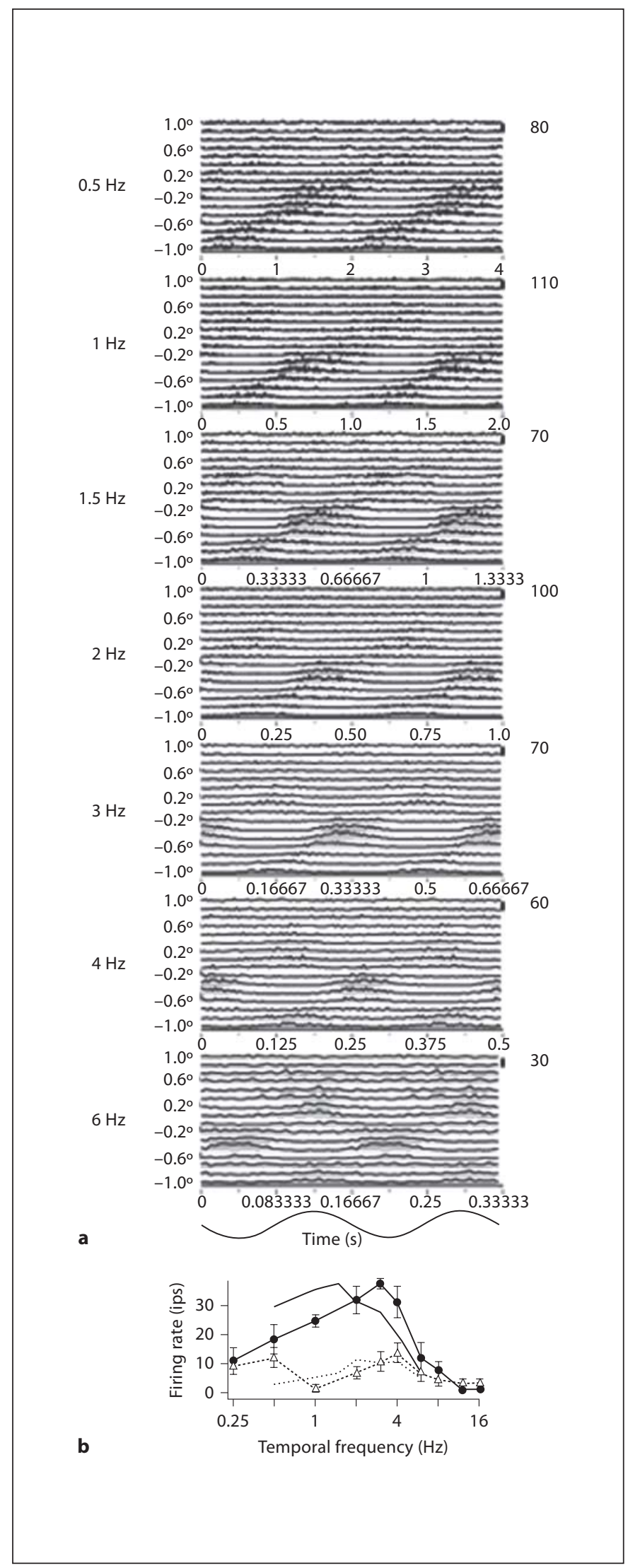

Neurosignals 2008;16:209-225 
to various degrees at $4 \mathrm{~Hz}$ and above [44]. The temporal frequency tuning of direction selectivity in visual cortical cells appears to match what one would expect if lagged and nonlagged cells in the LGN provided the spatiotemporally separated inputs underlying the direction selectivity.

This match between timing and the temporal frequency tuning of direction selectivity holds up under several other conditions. During postnatal development, kitten geniculate neurons progress from being largely sustained with long latencies to having clear lagged and nonlagged responses that can be both sustained and transient. A delayed emergence of inhibition might explain the development of both transient (late inhibition) and lagged (early inhibition) cells. The development of timing correlates with the development of the temporal frequency tuning of direction selectivity [16]. As first noted by Hubel and Wiesel [45], direction selectivity is present at eye-opening. However, it is often tuned to high temporal frequencies in young kittens, as expected based on the uniformly sustained timing and large latency variance.

Timing in monkey LGN differs from that in cats [Saul and Humphrey, unpubl.]. Latencies are shorter and do not vary with absolute phase. Since inputs with different phase at low frequencies have similar latencies, direction selectivity tends to be preserved across frequencies. Many cells in monkey $\mathrm{V} 1$ are direction selective only at high temporal frequencies, unlike cat V1.

\section{Directions for Future Research}

Lagged cells have been shown to exist only in cat and monkey LGN. Comparative studies remain to be done. The characteristic triadic synaptic arrangement in the LGN that presumably supports lagged cell responses exists throughout sensory thalamus in many species [4652]. The straightforward search for lagged cells in these animals, and in other sensory modalities, might shed further light on the mechanisms underlying lagged responses, and could provide more evidence related to their functions. In particular, rodents make useful models, with molecular studies in mice being particularly important.

The sketch of possible mechanisms producing lagged responses leaves many questions unanswered. Biophysical, pharmacological, and electrophysiological data need to be acquired to address how lagged cells are driven by their retinal inputs. Intracellular recording in vivo can answer some questions, but work in slice preparations would be a more productive way to look at the details of the synaptic and cellular processes involved. Unfortunately, lagged cells are defined by physiological criteria that are not available in a slice preparation (visual response properties and corticogeniculate latencies), so that the first problem is to find a way to identify lagged cells in a dish. A reliable biochemical marker of lagged or nonlagged cells would be helpful. Selectively inactivating one of these pathways could provide definitive information as to their influence on cortex.

\section{Lessons for Brain Research}

One of the simplest dichotomies in neuroscience is the characterization of synapses as excitatory or inhibitory. Even though it is clear that this is a huge simplification, much thinking about the brain relies on these two possibilities. Synapses are considered to either make postsynaptic firing more likely or less likely. One of the lessons of lagged cells is that inhibition does not just turn off firing. Instead, the main effect of the powerful feedforward inhibition is to alter response timing. Related views of inhibition have been expressed in applications to other systems [53-56]. These concepts have been hinted at often, but what is required are methods of rigorously measuring response timing, in order to fully appreciate the importance of time and the effects of inhibition on timing as opposed to response strength.

A recurring theme in recent investigations of sensory thalamic processing is that the classic view of the thalamus as a gateway to cortex with little effect on the signals it relays must be modified to encompass new insights into the circuitry. Lagged cells represent the clearest example where thalamic processing alters its input in a fundamental way. The LGN receives retinal input with nonlaggedtype timing and relays this relatively faithfully to cortex, but it sends an additional signal from lagged cells following a radical temporal transformation of the input. One reason the function of the thalamus may not have been apparent sooner is that the importance of time has been insufficiently appreciated.

Despite numerous studies of the LGN, lagged cells were not recognized until Mastronarde's work. The primary reason for missing this story for all those years is probably the effect of electrode sampling. Single-unit recording experiments have traditionally relied on low-impedance microelectrodes [57]. These electrodes easily record neural activity in a variety of structures. However, they only isolate large cells. Signals from small neurons 
are swamped by activity from surrounding cells $[9,58]$. We experienced the sampling differences between micropipettes with different impedances dozens of times [13]. We routinely located the LGN in an initial penetration with a pipette filled with $3 \mathrm{M} \mathrm{KCl}$ having an impedance of around $20 \mathrm{M} \Omega$. These electrodes almost never record from lagged cells. We subsequently used pipettes pulled and beveled identically but filled with $0.2 \mathrm{M} \mathrm{KCl}$, having impedances around $70 \mathrm{M} \Omega$. The higher impedance results in reliably recording lagged cells at an encounter rate of about $30 \%$. Mastronarde [12], Heggelund and Hartveit [pers. commun.], and Wolfe and Palmer [15] describe similar experiences with Levick electrodes, and only 3 out of dozens of Reitboeck electrodes have picked up lagged cells in monkey LGN [Saul, unpubl.]. Humphrey and Weller [8] demonstrated that lagged cells are small cells, consistent with their long antidromic latencies and fine axons, so it appears that soma size is the determining factor in sampling.

The fact that physiological studies that try to estimate properties of cell populations by sampling with microelectrodes have this potential bias can be disturbing. This problem should not negate studies subject to sampling biases, however, but should raise the possibility that they could be extended to include small cells where they exist. On the other hand, where a soma size difference is associated with the physiological variables being studied, frequencies of cell types derived from recording should be treated cautiously.

The final point with regard to the relevance of the lagged cell story for general neuroscience concerns neural modeling. The interaction of the work described here with theory is instructive. Work by Reichardt and colleagues [59-61], Barlow and Levick [62], and Marr and Ullman [63] led to a series of important papers [64-66] that detailed the spatiotemporal quadrature model in several forms. These contributions were inspired by some physiology, but were based largely on psychophysics and pure modeling. The key insight was that direction selectivity could be produced in a somewhat nonintuitive way from non-direction selective inputs. The recognition of lagged cells naturally led to the questions of whether lagged and nonlagged cells might be in quadrature and whether they contributed to the generation of direction selectivity in cortex.

Although theory played an important role in these results, none of these theoretical studies that aimed to explain cortical direction selectivity posited anything resembling lagged cells in the LGN. Most speculation focused on intracortically generated delays of some kind. Nobody suggested that temporal quadrature signals might originate in the LGN, or even that special mechanisms were needed to obtain quadrature at low temporal frequencies. These limitations can be ascribed to a lack of data, and this is the argument that neuroscience is still at an immature state in the sense of expecting theory to contribute much. However, even in the presence of the data reviewed above, modelers have continued to posit mechanisms for direction selectivity that ignore the diverse timing of the geniculate input to cortex, suggesting instead that NMDA or $\mathrm{GABA}_{B}$ receptors or synaptic depression might underlie cortical direction selectivity [6771]. The lesson is that the data available can be combined effectively with theory, but we cannot hope to guess how the brain works without intimate familiarity with experimental results.

\section{Acknowledgements}

I thank David Mastronarde, Allen Humphrey, Paul Heggelund, and Espen Hartveit for comments as well as for their pioneering work. Many of the ideas presented here are theirs.

\section{References}

1 Hubel DH, Wiesel TN: Integrative action in the cat's lateral geniculate body. J Physiol 1961; 155:385-398.

-2 Hubel DH, Wiesel TN: Receptive fields of single neurones in the cat's striate cortex. J Physiol 1959;148:574-591.

3 Humphrey AL, Saul AB: The temporal transformation of retinal signals in the lateral geniculate nucleus of the cat: implications for cortical function; in Minciacchi D, Molinari M, Macchi G, Jones EG (eds): Thalamic Networks for Relay and Modulation. Oxford, Pergamon, 1993, pp 81-89.
4 Humphrey AL, Saul AB: The emergence of direction selectivity in cat primary visual cortex; in Payne BR, Peters A (eds): Cat Primary Visual Cortex. New York, Academic Press, 2002, pp 343-386.

5 Enroth-Cugell C, Robson JG: The contrast sensitivity of retinal ganglion cells of the cat. J Physiol (Lond) 1966;187:517-552.
6 Guillery RW: A study of Golgi preparations from the dorsal lateral geniculate nucleus of the adult cat. J Comp Neurol 1966;128:2150.

7 Friedlander MJ, Lin C-S, Stanford LR, Sherman SM: Morphology of functionally identified neurons in lateral geniculate nucleus of the cat. J Neurophysiol 1981;46:80-129.

-8 Humphrey AL, Weller RE: Structural correlates of functionally distinct X-cells in the lateral geniculate nucleus of the cat. J Comp Neurol 1988;268:448-468. 
-9 Stone J: Sampling properties of microelectrodes assessed in the cat's retina. J Neurophysiol 1973;36:1071-1079.

$\checkmark 10$ Crick F: Function of the thalamic reticular complex: the searchlight hypothesis. Proc Natl Acad Sci USA 1984;81:4586-4590.

-11 Mastronarde DN: Two classes of single-input $\mathrm{X}$-cells in cat lateral geniculate nucleus. II. Retinal inputs and the generation of receptive field properties. J Neurophysiol 1987;57: 381-413.

12 Mastronarde DN: Two classes of single-input $\mathrm{X}$-cells in cat lateral geniculate nucleus. I. Receptive field properties and classification of cells. J Neurophysiol 1987;57:357-380.

-13 Humphrey AL, Weller RE: Functionally distinct groups of $\mathrm{X}$-cells in the lateral geniculate nucleus of the cat. J Comp Neurol 1988; 268:429-447.

14 Cai D, DeAngelis GC, Freeman RD: Spatiotemporal receptive field organization in the lateral geniculate nucleus of cats and kittens. J Neurophysiol 1997;78:1045-1061.

-15 Wolfe J, Palmer LA: Temporal diversity in the lateral geniculate nucleus of cat. Vis Neurosci 1998; 15:653-675.

16 Saul AB, Feidler JC: Development of response timing and direction selectivity in cat visual thalamus and cortex. J Neurosci 2002; 22:2945-2955.

-17 Mastronarde DN, Humphrey AL, Saul AB: Lagged Y cells in the cat lateral geniculate nucleus. Vis Neurosci 1991;7:191-200.

-18 Tang Y, Saul AB, Gur M, Goei S, Wong E, Ersoy B, Snodderly DM: Eye position compensation improves estimates of response magnitude and receptive field geometry in alert monkeys. J Neurophysiol 2007;97: 3439-3448.

$\checkmark 19$ Heggelund P, Hartveit E: Neurotransmitter receptors mediating excitatory input to cells in the cat lateral geniculate nucleus. I. Lagged cells. J Neurophysiol 1990;63:1347-1360.

$\checkmark 20$ Hartveit E, Heggelund P: Neurotransmitter receptors mediating excitatory input to cells in the cat lateral geniculate nucleus. II. Nonlagged cells. J Neurophysiol 1990;63:13611372.

-21 Kwon YH, Esguerra M, Sur M: NMDA and non-NMDA receptors mediate visual responses of neurons in the cat's lateral geniculate nucleus. J Neurophysiol 1991;66:414428.

-22 Demeulemeester H, Arckens L, Vandesande F, Orban GA, Heizmann CW, Pochet R: Calcium binding proteins as molecular markers for cat geniculate neurons. Exp Brain Res 1991;83:513-520.

23 McCormick DA: Functional properties of a slowly inactivating potassium current in guinea pig dorsal lateral geniculate relay neurons. J Neurophysiol 1991;66:1176-1189.

-24 Augustinaite S, Heggelund P: Changes in firing pattern of lateral geniculate neurons caused by membrane potential dependent modulation of retinal input through NMDA receptors. J Physiol 2007;582:297-315.
25 Steriade M, Pare D, Hu B, Deschenes M: The visual thalamocortical system and its modulation by the brain stem core; in Ottoson D (ed): Progress in Sensory Physiology 10. Berlin, Springer, 1990.

26 Uhlrich DJ, Tamamaki N, Sherman SM Brainstem control of response modes in neurons of the cat's lateral geniculate nucleus. Proc Natl Acad Sci USA 1990;87:25602563.

27 Humphrey AL, Saul AB: Action of brain stem reticular afferents on lagged and nonlagged cells in the lateral geniculate nucleus. J Neurophysiol 1992;68:673-691.

28 Hartveit E, Heggelund P: Brain-stem influence on visual response of lagged and nonlagged cells in the cat lateral geniculate nucleus. Vis Neurosci 1993;10:325-339.

29 Hartveit E: Simultaneous recording of lagged and nonlagged cells in the cat dorsal lateral geniculate nucleus. Exp Brain Res 1992;88: 229-232.

30 Mastronarde DN: Nonlagged relay cells and interneurons in the cat lateral geniculate nucleus: receptive-field properties and retinal inputs. Vis Neurosci 1992;8:407-441.

31 Saul AB, Humphrey AL: Spatial and temporal response properties of lagged and nonlagged cells in the cat lateral geniculate nucleus. J Neurophysiol 1990;64:206-224.

32 Mitzdorf U, Singer W: Prominent excitatory pathways in the cat visual cortex (A17 and A18): a current source density analysis of electrically evoked potentials. Exp Brain Res 1978;33:371-394.

33 Leventhal AG: Evidence that the different classes of relay cells of the cat's lateral geniculate nucleus terminate in different layers of the striate cortex. Exp Brain Res 1979;37: 349-372.

34 Saul AB, Humphrey AL: Evidence of input from lagged cells in the lateral geniculate nucleus to simple cells in cortical area 17 of the cat. J Neurophysiol 1992b;68:1190-1207.

35 Reid RC, Soodak RE, Shapley RM: Linear mechanisms of directional selectivity in simple cells of cat striate cortex. Proc Natl Acad Sci USA 1987;84:8740-8744.

36 McLean J, Palmer LA: Contribution of linear spatiotemporal receptive field structure to velocity selectivity of simple cells in area 17 of cat. Vis Res 1989;29:675-679.

37 Albrecht DG, Geisler WS: Motion selectivity and the contrast-response function of simple cells in the visual cortex. Vis Neurosci 1991; 7:531-546.

38 Tolhurst DJ, Dean AF: Evaluation of a linear model of directional selectivity in simple cells of the cat's striate cortex. Vis Neurosci 1991;6:421-428.

39 DeAngelis GC, Ohzawa I, Freeman RD: Spatiotemporal organization of simple-cell receptive fields in the cat's striate cortex. II. Linearity of temporal and spatial summation. J Neurophysiol 1993;69:1118-1135.
40 Jagadeesh B, Wheat HS, Ferster D: Linearity of summation of synaptic potentials underlying direction selectivity in simple cells of the cat visual cortex. Science 1993;262:19011904.

41 McLean J, Raab S, Palmer LA: Contribution of linear mechanisms to the specification of local motion by simple cells in areas 17 and 18 of the cat. Vis Neurosci 1994;11:271-294.

42 Murthy A, Humphrey AL, Saul AB, Feidler JC: Laminar differences in the spatiotemporal structure of simple cell receptive fields in cat area 17. Vis Neurosci 1998;15:239-256.

43 Baker CL Jr: Linear filtering and nonlinear interactions in direction-selective visual cortex neurons: a noise correlation analysis. Vis Neurosci 2001;18:465-485.

-44 Saul AB, Humphrey AL: Temporal frequency tuning of direction selectivity in cat visual cortex. Vis Neurosci 1992a;8:365-372.

$\checkmark 45$ Hubel DH, Wiesel TN: Receptive fields in striate cortex of very young, visually inexperienced kittens. J Neurophysiol 1963;26: 994-1002.

46 Majorossy K, Kiss A: Specific patterns of neuron arrangement and of synaptic articulation in the medical geniculate body. Exp Brain Res 1976;26:1-17.

47 Somogyi Gy, Hajdu F, Tömböl T: Ultrastructure of the anterior ventral and anterior medial nuclei of the cat thalamus. Exp Brain Res 1978;31:417-431.

48 Ohara PT, Lieberman AR, Hunt SP, Wu JY: Neural elements containing glutamic acid decarboxylase (GAD) in the dorsal lateral geniculate nucleus of the rat; immunohistochemical studies by light and electron microscopy. Neuroscience 1983;8:189-211.

49 Blomqvist A, Flink R, Westman J, Wiberg M: Synaptic terminals in the ventroposterolateral nucleus of the thalamus from neurons in the dorsal column and lateral cervical nuclei: an electron microscopic study in the cat. J Neurocytology 1985;14:869-886.

50 So KF, Campbell G, Lieberman AR: Synaptic organization of the dorsal lateral geniculate nucleus in the adult hamster: an electron microscope study using degeneration and horseradish peroxidase tracing techniques. Anat Embryol (Berl) 1985;171:223-234.

51 Hamori J, Pasik P, Pasik T: Different types of synaptic triads in the monkey dorsal lateral geniculate nucleus. J Hirnforsch 1991;32: 369-379.

52 Ralston HJ 3rd, Ralston DD: Medial lemniscal and spinal projections to the macaque thalamus: an electron microscopic study of differing GABAergic circuitry serving thalamic somatosensory mechanisms. J Neurosci 1994;14:2485-2502.

53 Hicks TP, Metherate R, Landry P, Dykes RW: Bicuculline-induced alterations of response properties in functionally identified ventroposterior thalamic neurones. Exp Brain Res 1986;63:248-264. 
54 Fujita I, Konishi M: The role of GABAergic inhibition in processing of interaural time difference in the owl's auditory system. J Neurosci 1991;11:722-739.

55 Hooper SL, DiCaprio RA: Crustacean motor pattern generator networks. Neurosignals 2004; 13:50-69.

56 Santamaria F, Bower JM: Background synaptic activity modulates the response of a modeled purkinje cell to paired afferent input. J Neurophysiol 2005;93:235-250.

57 Hubel DH: Tungsten microelectrode for recording from single units. Science 1957;125: 549-550.

-58 Towe AL, Harding GW: Extracellular microelectrode sampling bias. Exp Neurol 1970; 29:366-381.

59 Reichardt W: Autocorrelation: a principle for the evaluation of sensory information by the central nervous system; in Rosenblith WA (ed): Sensory Communication. New York, MIT Press, 1961, pp 303-318.
60 Torre V, Poggio T: A synaptic mechanism possibly underlying directional selectivity to motion. Proc R Soc Lond [B] 1978;202:409416.

61 Borst A, Egelhaaf M: Principles of visual motion detection. Trends Neurosci 1989;12 297-306.

62 Barlow HB, Levick WR: The mechanism of directionally selective units in rabbit's retina. J Physiol (Lond) 1965;178:477-504.

63 Marr D, Ullman S: Direction selectivity and its use in early visual processing. Proc R Soc Lond [B] 1981;211:151-180.

64 Adelson EH, Bergen JR: Spatiotemporal en ergy models for the perception of motion. J Opt Soc Am [A] 1985;2:284-299.

65 van Santen JPH, Sperling G: Elaborated Reichardt detectors. J Opt Soc Am [A] 1985; 2:300-321.

66 Watson AB, Ahumada AJ Jr: Model of human visual-motion sensing. J Opt Soc Am A $1985 ; 2: 322-342$
67 Suarez H, Koch C, Douglas R: Modeling direction selectivity of simple cells in striate visual cortex within the framework of the canonical microcircuit. J Neurosci 1995;15: 6700-6719.

68 Maex R, Orban GA: Model circuit of spiking neurons generating directional selectivity in simple cells. J Neurophysiol 1996;75:15151545.

69 Chance FS, Nelson SB, Abbott LF: Synaptic depression and the temporal response characteristics of V1 cells. J Neurosci 1998;18: 4785-4799.

70 Livingstone MS: Mechanisms of direction selectivity in macaque V1. Neuron 1998;20: 509-526.

71 Sabatini SP, Solari F: An architectural hypothesis for direction selectivity in the visual cortex: the role of spatially asymmetric intracortical inhibition. Biol Cybern 1999;80: 171-183. 